DOI 10. 18307/2021. 0307

(C) 2021 by Journal of Lake Sciences

\title{
洪泽湖养殖网围拆除生态效应
}

\author{
段海昕 ${ }^{1}$, 毛志刚 ${ }^{2}$, 王国祥 ${ }^{1 * *}$, 谷孝鸿 ${ }^{2}$, 曾庆飞 ${ }^{2}$, 陈辉辉 ${ }^{2}$ \\ ( 1 : 南京师范大学环境学院, 南京 210023) \\ (2: 中国科学院南京地理与湖泊研究所湖泊与环境国家重点实验室,南京 210008)
}

\begin{abstract}
摘 要: 为研究湖泊网围养殖对湖泊生态系统的影响, 2018 年全年 3 次于洪泽湖养殖网围及主要出人湖河道开展调查, 通过对比洪泽湖不同区域 (河口、湖心、网围区、外围区和拆除区) 水质及水生生物的空间分布特征, 分析养殖网围拆除后 湖泊生态系统的响应机制. 结果表明, 洪泽湖不同区域的水质及水生生物群落结构存在明显差异, 其中养殖区水体总氮、 总磷及悬浮颗粒物浓度明显低于河口和湖心, 但浮游动植物密度及生物量则整体高于河口和湖心, 且养殖区蓝藻、轮虫 所占比重较高, 这种分布差异很大程度上受外源输人及水动力条件影响. 与之相对, 养殖区内网围区、拆除区和外围区的 水质及水生生物群落结构差异并不明显, 表明养殖网围拆除后的短期时间内水质并未明显改善, 且高藻类密度、低透明 度的水体环境也不利于沉水植物的萌发生长与群丛恢复, 有必要进一步采取合理有效的生态修复措施促进养殖迹地生 态系统的恢复.
\end{abstract}

关键词 : 网围养殖;水质;水生生物;生态效应;洪泽湖

\section{Ecological effects on enclosure culture demolition of Lake Hongze *}

Duan Haixin $^{1}$, Mao Zhigang ${ }^{2}$, Wang Guoxiang ${ }^{1 * *}$, Gu Xiaohong ${ }^{2}$, Zeng Qingfei $^{2}$ \& Chen Huihui ${ }^{2}$

(1: School of Environment, Nanjing Normal University, Nanjing 210023, P.R.China)

(2: State Key Laboratory of Lake Science and Environment, Nanjing Institute of Geography and Limnology, Chinese Academy of Sciences, Nanjing 210008, P.R. China)

Abstract: In order to investigate the ecological effects of enclosure culture on the lake ecosystem, the investigation was carried out three times in the enclosure culture of Lake Hongze and its inlets and outlets during 2018. The response mechanism of the lake ecosystem after enclosure culture demolition was analyzed based on the data accumulated by comparing the spatial distribution characteristics of water quality parameters, the phytoplankton, zooplankton, and benthos communities in different areas of Lake Hongze (estuary, lake center, enclosure area, peripheral area, and demolition area). The results show that there are obvious differences between water quality and aquatic organisms in different lake regions. The concentrations of total nitrogen, total phosphorus, and suspended particulate matter in the samples collected within the culture areas are slightly higher than samples collected in the estuary and lake center, but both density and biomass of the phytoplankton are lower in the culture areas than those in the estuary and lake center. The proportion of Cyanophyta and rotifers in the culture areas is higher than that in the estuary and lake center. This distribution difference is largely affected by external input and hydrodynamic conditions. On the contrary, the differences in water quality and aquatic organisms between various areas of the enclosure culture are not considerable, indicating that the water quality has not improved significantly in the short period after the enclosure culture is removed. And the water quality with high algae density and low transparency will be detrimental to submerged plant growth and community recovery. Therefore, it's necessary to take further rational and effective ecological restoration measures to promote the restoration of the enclosure culture ecosystems.

Keywords: Enclosure culture; water quality; aquatic organisms; ecological effects; Lake Hongze

* 2020-05-27 收稿; 2020-09-23 收修改稿.

江苏省治太科研课题项目( TH2019303)、内蒙古自治区科技重大专项课题项目(ZDZX2018054)和国家自然科学基 金项目 (31870449) 联合资助.

** 通信作者;E-mail: wangguoxiang@ njnu.edu.cn. 
洪泽湖作为中国第四大淡水湖泊, 不仅在气候调节、洪涝控制、居民用水等方面发挥着重要作用, 更有 着丰富的水生生物和渔业资源 ${ }^{[1-2]}$. 自 1980s 以来, 洪泽湖网围养殖渔业规模不断扩大; 但由于缺乏科学指导 和合理规划, 导致湖区水体环境质量不断下降, 湖泊生态系统逐步退化 ${ }^{[3]}$. 国内学者此前对洪泽湖区域的水 质变化、水生生物分布及变化特征进行了大量的研究,例如吴天浩等 ${ }^{[4]}$ 曾对洪泽湖湖区浮游植物群落结构 进行调查研究, 并进行相关生态学评价, 都雪等 ${ }^{[5]}$ 对洪泽湖轮虫群落结构进行调查并分析其季节分布, 蔡永 久等 ${ }^{[6]}$ 也对现阶段洪泽湖大型底栖动物群落现状及其多样性进行调查研究.

自上世纪末以来, 淡水养殖渔业快速发展, 湖泊水库等水体资源被大规模利用, 网围养殖逐渐成为我国 淡水养殖的重要模式之一,但网围养殖伴随的养殖水域水环境恶化及水生生物栖息生境遭到破坏等问题逐 渐受到学者和环保人士的关注 ${ }^{[7]}$, 包括网围养殖过程中产生的大量养殖污染物, 包括饵料残渣、固体废物和 化学农药等. 因此, 近年来洪泽湖开始大规模拆除养殖网围, 以此缓解洪泽湖水质污染现状, 以修复养殖迹 地生态环境及生态功能. 之前已有学者讨论过太湖等湖泊网围养殖模式优化对水质及浮游植物、浮游动物 的影响 ${ }^{[8]}$, 但是关于湖泊养殖网围拆除后水质及水生生物群落的响应特征变化尚缺乏足够报道. 本文拟结 合洪泽湖养殖网围拆除工程, 分析网围拆除后水质、底质及浮游生物、底栖动物等生物群落结构的变化趋势 及相互关系, 以此探讨湖泊养殖网围拆除的整体生态环境效应, 为修复湖泊养殖迹地生态功能及生态系统 提供科学的理论依据.

\section{1 研究区域与方法}

\section{1 研究区域概况}

洪泽湖 ( $33^{\circ} 06^{\prime} \sim 33^{\circ} 40^{\prime} \mathrm{N}, 118^{\circ} 10^{\prime} \sim 118^{\circ} 52^{\prime} \mathrm{E}$ ) 位于 江苏省西部, 淮河中下游结合部. 洪泽湖水域面积约为 $1597 \mathrm{~km}^{2}$, 最大水深 $4.37 \mathrm{~m}$, 平均水深 $1.77 \mathrm{~m}$, 最大宽 55.0 $\mathrm{km}$, 平均宽 $24.26 \mathrm{~km}$, 全长 $65.0 \mathrm{~km}$. 湖水来源主要依靠地 表径流,环湖有包括淮河、濉河、洪河、和安东河等 8 条主 要人湖河流 ${ }^{[9]}$. 本次调查于 2018 年 5 月 (中水位)、7 月 (低水位)、12 月(高水位) 共进行 3 次采样. 根据洪泽湖养 殖网围及主要出人湖河道的分布特征设置 19 个采样点 位,各点位的位置如图 1 所示: 河口 (H1、H8、H17、H18、 $\mathrm{H} 19)$; 湖心 $(\mathrm{H} 15 、 \mathrm{H} 16)$; 养殖区中的网围区 $(\mathrm{H} 2 、 \mathrm{H} 5 、 \mathrm{H} 9$ 、 H12)、拆除区 $(H 3 、 H 6 、 H 10 、 H 13)$ 和外围区 $(H 4 、 H 7 、 H 11$ 、 H14) (本次调查的网围拆除区集中于 $2015-2017$ 年拆 除).

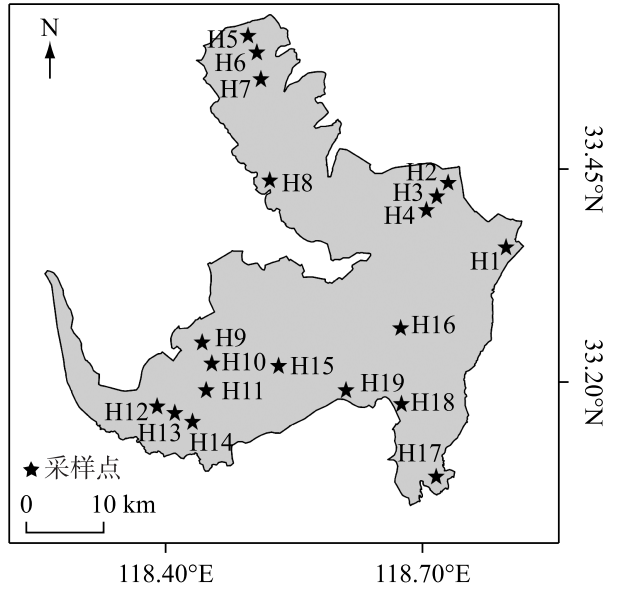

图 1 洪泽湖采样点位分布

Fig.1 Distribution of sampling sites in Lake Hongze

\section{2 水样及沉积物样品采集与分析}

使用 YSI 水质分析仪测定水温 $(\mathrm{T}) 、 \mathrm{pH}$ 、溶解氧 ( DO ) 浓度等水质指标; 水体透明度 $(\mathrm{SD})$ 使用塞氏盘现 场测定; 悬浮颗粒物 (SS)、总氮 (TN)、总磷 (TP)、溶解性总氮 (DTN)、溶解性总磷 (DTP)、高锰酸盐指数 $\left(\mathrm{COD}_{\mathrm{Mn}}\right)$ 和叶绿素 $a(\mathrm{Chl} . a)$ 浓度等指标参照《湖泊富营养化调查规范》 ${ }^{[10]}$ 用采集后的湖泊水样测定.

水样沉积物中的 TN、TP 浓度, 使用原子发射光谱仪 (ICP-AES) 进行测定, 柱状采泥器采集湖泊沉积物 表层样品约 $0 \sim 5 \mathrm{~cm}$ 后, 带回实验室进行风干、研磨、过篮等预处理后测定.

\section{3 生物样品采集与分析}

轮虫和浮游植物样品采集自水深 $20 \mathrm{~cm}$ 处, 水样装入聚乙烯瓶中, 并立刻加人鲁哥试剂固定, 带回实验室 经过 $48 \mathrm{~h}$ 静止沉淀后浓缩, 用于种类鉴定及计数; 采集水样 $5 \mathrm{~L}$, 经过 $25^{\#}$ 浮游生物网过滤, 而后用福尔马林溶 液固定, 经过 $48 \mathrm{~h}$ 静置沉淀后浓缩, 进行枝角类和桡足类浮游动物种类鉴定和计数; 采样中使用 $1 / 16 \mathrm{~m}^{2}$ 彼得 森采泥器抓取底泥, 装人贴有标签的自封袋中, 而后立即篮洗所采集样品, 带回实验室后将底栖动物逐一捡 出, 用福尔马林溶液固定, 然后进行底栖动物种类鉴定、计数和称重. 生物样品的种类鉴定参考《中国淡水藻 类一一系统、分类及生态》 ${ }^{[11]}$ 、 《中国淡水轮虫志》 ${ }^{[12]}$ 和《淡水无脊椎动物系统分类、生物及生态学》 ${ }^{[13]}$. 


\section{4 数据处理与分析}

Margalef 丰富度指数 $(D) 、$ Shannon-Wiener 多样性指数 $\left(H^{\prime}\right) 、$ Pielou's evenness 均匀度指数 $\left(J^{\prime}\right)^{[14]}$ 用于分 析水生生物多样性,采用计算公式为:

$$
\begin{gathered}
D=(S-1) / N \\
H^{\prime}=-\sum_{i=1}^{S} P_{i} \cdot \ln \left(P_{i}\right) \\
J^{\prime}=H^{\prime} / \ln (S)
\end{gathered}
$$

式中, $S$ 为水生生物样品中某种类种类数, $N$ 为总个数, $P_{i}$ 为第 $i$ 种所占的比例.

水生生物多样性依据 $H^{\prime}$ 数值大小可分为极贫乏、贫乏、一般、较丰富、丰富, 参考国家环境保护标准 $(\mathrm{HJ}$ $442-2008)$.

水生生物群落优势种采用 Pinkas 等 ${ }^{[15]}$ 的相对重要指数 (IRI) 进行比较分析:

$$
I R I=(N \%+W \%) F \%
$$

式中, $N \%$ 为水生生物中某种类个数占总个数的百分比, $W \%$ 为某种类质量占总质量的百分比, $F \%$ 为某种类 出现点位数占总点位数的百分比. 本研究中选取 IRI 值大于 500 的种类为优势种.

各组数据之间差异性通过 SPSS 22.0 软件进行分析, 主要采用方差分析、多重比较等分析方法, 差异性 水平选择 $P<0.05$.

\section{2 结果与讨论}

\section{1 养殖网围拆除对水质及底质的影响}

洪泽湖各区域水体和沉积物理化参数全年平均值如表 1 所示. 沉积物中 TN 和 TP 含量分别为 $0.80 \sim$ 2.32 和 $0.56 \sim 0.73 \mathrm{mg} / \mathrm{g}$; 水体中 $\mathrm{TN}$ 浓度变化范围为 $1.46 \sim 2.51 \mathrm{mg} / \mathrm{L}$, TP 浓度变化范围为 $60.36 \sim 124.64 \mu \mathrm{g} /$ $\mathrm{L}$, 整体为 $\mathrm{IV} \sim \mathrm{V}$ 类水水质标准. 养殖区 (网围区、拆除区、外围区) 沉积物中 $\mathrm{TN}$ 含量显著高于河口和湖心 $(P$ $<0.05)$, 而养殖区内各区域差异不大. 这可能是由于在网围养殖过程中, 过量添加的饲料及鱼类的代谢活动 产物沉积至湖泊底质, 致使养殖区营养盐浓度累计显著高于河口和湖心 ${ }^{[16]}$, 这与何肖微等在东太湖网围养

\begin{tabular}{|c|c|c|c|c|c|c|}
\hline & 指标 & 河口 & 湖心 & 网围区 & 拆除区 & 外围区 \\
\hline \multirow[t]{10}{*}{ 水体 } & 透明度/cm & $43 \pm 9$ & $40 \pm 3$ & $56 \pm 7$ & $63 \pm 12$ & $50 \pm 5$ \\
\hline & $\mathrm{pH}$ & $8.6 \pm 0.2$ & $8.8 \pm 0.1$ & $8.9 \pm 0.2$ & $8.9 \pm 0.1$ & $8.9 \pm 0.1$ \\
\hline & $\mathrm{SS} /(\mathrm{mg} / \mathrm{L})$ & $51.3 \pm 28.1$ & $35.6 \pm 5.8$ & $26.8 \pm 10.1$ & $25.4 \pm 8.9$ & $32.7 \pm 5.5$ \\
\hline & $\mathrm{TN} /(\mathrm{mg} / \mathrm{L})$ & $2.51 \pm 0.36$ & $2.20 \pm 0.26$ & $1.46 \pm 0.19$ & $1.51 \pm 0.10$ & $1.56 \pm 0.08$ \\
\hline & $\mathrm{DTN} /(\mathrm{mg} / \mathrm{L})$ & $2.32 \pm 0.38$ & $1.97 \pm 0.34$ & $1.09 \pm 0.17$ & $1.14 \pm 0.11$ & $1.17 \pm 0.16$ \\
\hline & $\mathrm{NH}_{3}-\mathrm{N} /(\mathrm{mg} / \mathrm{L})$ & $0.26 \pm 0.13$ & $0.16 \pm 0.02$ & $0.13 \pm 0.02$ & $0.12 \pm 0.03$ & $0.12 \pm 0.01$ \\
\hline & $\mathrm{TP} /(\mu \mathrm{g} / \mathrm{L})$ & $124.64 \pm 42.96$ & $98.44 \pm 4.81$ & $73.81 \pm 19.29$ & $60.36 \pm 4.94$ & $62.46 \pm 9.35$ \\
\hline & $\mathrm{DTP} /(\mu \mathrm{g} / \mathrm{L})$ & $52.28 \pm 14.16$ & $54.38 \pm 11.12$ & $28.02 \pm 4.43$ & $21.18 \pm 4.62$ & $21.69 \pm 2.69$ \\
\hline & $\mathrm{COD}_{\mathrm{Mn}} /(\mathrm{mg} / \mathrm{L})$ & $9.5 \pm 3.6$ & $11.7 \pm 0.2$ & $8.8 \pm 2.5$ & $9.3 \pm 4.0$ & $7.8 \pm 2.8$ \\
\hline & Chl. $a /(\mu \mathrm{g} / \mathrm{L})$ & $19.6 \pm 18.3$ & $15.3 \pm 9.1$ & $38.6 \pm 18.4$ & $36.1 \pm 9.9$ & $44.6 \pm 11.9$ \\
\hline \multirow[t]{2}{*}{ 沉积物 } & $\mathrm{TN} /(\mathrm{mg} / \mathrm{g})$ & $0.80 \pm 0.55$ & $0.86 \pm 0.02$ & $2.03 \pm 0.62$ & $2.32 \pm 1.45$ & $1.60 \pm 0.76$ \\
\hline & $\mathrm{TP} /(\mathrm{mg} / \mathrm{g})$ & $0.65 \pm 0.11$ & $0.73 \pm 0.04$ & $0.70 \pm 0.25$ & $0.56 \pm 0.07$ & $0.56 \pm 0.02$ \\
\hline
\end{tabular}
殖区的研究结果相一致 ${ }^{[8]}$.

\section{表 1 洪泽湖不同区域水体与沉积物的主要理化参数}

Tab.1 Main physical and chemical parameters of water and sediment in different regions of Lake Hongze

与沉积物营养盐含量分布趋势相反, 河口和湖心水体中的 TN 、TP、DTN、DTP 浓度均显著高于养殖区 $(P<0.05)$, 且河口和湖心的 SS 浓度也表现出一致的分布特征. 水动力或风速条件引起的沉积物再悬浮可能 是造成水体营养盐和 SS 浓度空间分布差异的主要原因 ${ }^{[17]}$, 河口和湖心的氮、磷浓度受外源输人和沉积物再 悬浮影响较大. 朱伟等 ${ }^{[18]}$ 研究发现风浪扰动引起的底质再悬浮, 也是造成水体中营养盐浓度及水体透明度 
下降的重要原因,这与本研究结果一致.

与 TN 、TP 分布趋势相反, 网围养殖区水体 Chl. $a$ 浓度范围为 $15.3 \sim 44.6 \mu \mathrm{g} / \mathrm{L}$, 显著高于湖心和河口 $(P<$ $0.05)$, 这可能是由于养殖区较河口和湖心具有更利于藻类生长的水动力条件, 即风浪扰动较弱, 透明度相 对较高 ${ }^{[19]}$. 另一方面, 水体中氮、磷营养盐被养殖区内大量增殖的藻类吸收利用, 这也是造成河口和湖心与 养殖区营养盐浓度分布差异的原因之一. 与之相对, 养殖区内网围区、拆除区和外围区的水质差异并不明 显, 这可能是由养殖区周围水体的连通性造成的 ${ }^{[20]}$. 薛俊增等 ${ }^{[21]}$ 对于淀山湖的研究中也发现养殖网围拆除 后, 养殖区水质并无根本性的转变. 但 Luo 等 ${ }^{[22]}$ 对阳澄湖长期的研究表明网围养殖面积与水体中 TN、TP 等 营养盐浓度呈显著正相关,这表明网围拆除后生态系统水质的恢复往往需要较长的时间.

\section{2 养殖网围拆除对水生生物的影响}

2.2.1 浮游植物群落变化 本次调查共鉴定出浮游植物 109 种, 隶属 8 门, 其中绿藻门 ( 56 种) 种类最多, 占 浮游植物总数的 $51.4 \%$; 其次是蓝藻门 ( 20 种)、硅藻门 ( 18 种) 和裸藻门 ( 5 种), 分别占总数的 $18.3 \%$ 、 $16.5 \%$ 和 $4.6 \%$; 金藻门 ( 3 种)、黄藻门 ( 2 种)、甲藻门 ( 2 种) 和隐藻门 ( 3 种) 的种类数较少. 比较洪泽湖不同 水域的浮游植物种类组成, 结果显示河口、湖心、网围区、拆除区和外围区这 5 个区域均以蓝藻、绿藻和硅藻 为主 (图 2), 但养殖区的藻类种类数相对高于湖心和河口, 一些常见种类如隶属于蓝藻门的微囊藻
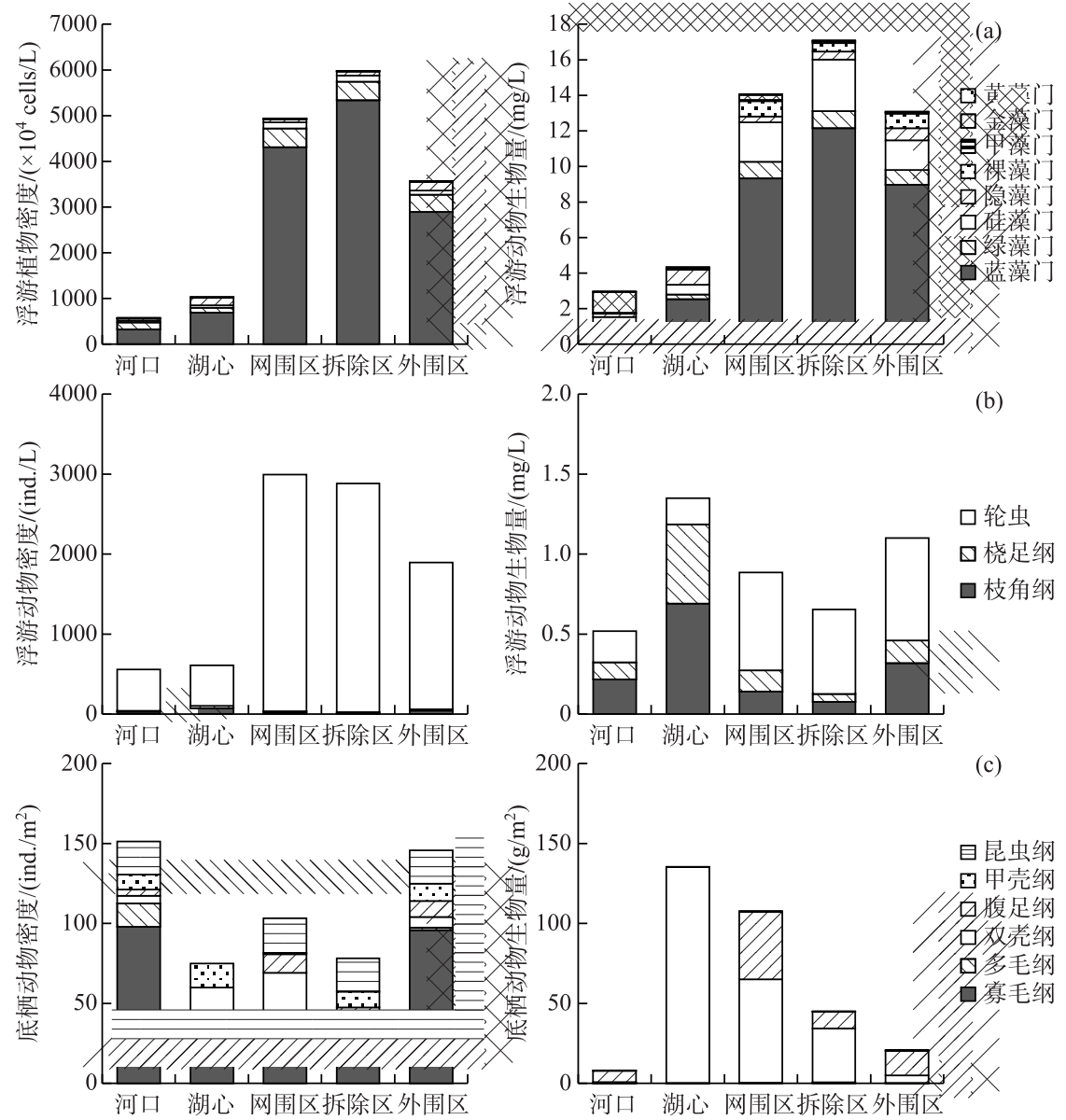

图 2 洪泽湖不同区域浮游植物 ( $\mathrm{a}$ )、浮游动物 ( b ) 和大型底栖动物 ( $\mathrm{c}$ ) 的密度及生物量 (2018 年均值)

Fig.2 Density and biomass of phytoplankton (a), zooplankton (b), macrobenthos (c) in different regions of Lake Hongze ( annual mean value of 2018) 
(Microcystis sp.), 隶属于绿藻门的弓形藻 (Schroederia sp.), 隶属于硅藻门的针杆藻 (Synedra sp.) 以及隶属于 隐藻门的尖尾蓝隐藻 (Chroomonas acuta) 等在多数点位均有发现.

洪泽湖不同水域间浮游植物的密度和生物量存在明显差别 (图 2a), 其中养殖区浮游植物现存量远高于 湖心和河口, 而养殖区内的网围区、拆除区和外围区在密度和生物量组成上差异并不明显, 这也与 Chl. $a$ 浓 度的分布趋势相一致 (表 1). 大量研究证明, 浮游植物空间异质性主要是由水动力条件和底层差异造成 的 ${ }^{[23-24]}$. 较强水动力条件造成底质悬浮、水体浊度增大, 影响浮游植物光合作用速率, 最终减弱浮游植物生 物量的累积, 导致浮游植物生物量的降低 ${ }^{[25]}$. 除此之外, 较强的水动力条件下的高剪切力还会造成浮游植 物细胞的破坏, 亦不利于浮游植物细胞的生长增殖, 导致浮游植物生物量降低 ${ }^{[26]}$. 同时, 养殖区沉积物中的 $\mathrm{TN}$ 含量显著高于湖心和河口 (表 1), 底质向水体中不断释放的营养盐差异也是造成浮游植物空间异质性的 原因 ${ }^{[27]}$.

从浮游植物群落结构上分析, 养殖区内各区域均以蓝藻为主, 生物量占比达 $66 \% \sim 71 \%$; 而湖心、河口的 蓝藻比重下降, 隐藻、金藻的比重增加. 洪泽湖不同区域间浮游植物的优势种及优势度亦存在差别 (表 2), 其中养殖区的优势种基本为蓝藻门, 而河口和湖心的优势种类别增加, 出现绿藻门、硅藻门和隐藻门, 这可 能是河口和湖心流动性相对养殖区较高, 蓝藻水华不易堆积繁殖的结果 ${ }^{[28]}$. 此外, 光照条件也是浮游植物 群落结构差异的间接影响因素 ${ }^{[29]}$. 例如, 在养殖区这样较弱的水动力条件下, 悬浮在水体表面的蓝藻会阻 挡光线进人水体, 从而影响水体中其他藻类对于光照的利用、光合作用的进行及生物量的累积 ${ }^{[30]}$; 而硅藻等 因为具有较强适应能力以及抗风浪扰动能力, 从而在湖心等强水动力条件下成为优势藻类 ${ }^{[29]}$. 而养殖区内 浮游植物群落结构差异并不明显. 综上所述, 养殖网围拆除后, 其水体环境仍为高藻类密度、低透明度型水 体, 不利于沉水植物的萌发生长与群丛恢复, 因此有必要采取进一步合理有效的生态修复技术促进养殖迹 地的生态系统恢复.

此外, 洪泽湖浮游植物 $D 、 H^{\prime}$ 和 $J^{\prime}$ 的计算结果如表 3 显示, 各区域浮游植物多样性均表现为较丰富. 洪泽 湖各水域基于个体数量的多样性指标 $H^{\prime}{ }_{\mathrm{N}} 、 J^{\prime}{ }_{\mathrm{N}}$ 与基于生物量的多样性指标 $H^{\prime}{ }_{\mathrm{W}} 、 J^{\prime}{ }_{\mathrm{W}}$ 之间无明显差异, 且洪泽 湖不同水域的各项多样性指数亦无显著差异 $(P<0.05)$, 这表明湖区内的浮游植物群落中小个体与大个体种 类均占据一定优势 ${ }^{[31]}$, 这也与单个细胞体积较小的蓝藻和个体较大的硅藻均占较大比例相一致.

表 2 洪泽湖不同区域水生生物前 5 优势种组成 (IRI) 与排序*

Tab.2 Composition and ranking of the top five dominant species of aquatic organisms in different regions of Lake Hongze

\begin{tabular}{|c|c|c|c|c|c|c|c|c|}
\hline 排序 & 种类 & 拉丁学名 & 网围区 & 拆除区 & 外围区 & 河口 & 湖心 & 合计 \\
\hline 1 & 小颤藻 & Oscillatoria tenuis & $4408(1)$ & $4826(1)$ & $4029(1)$ & $1927(1)$ & $2828(1)$ & 5 \\
\hline 2 & 颤藻属 & Oscillatoria sp. & $1936(3)$ & $1634(4)$ & $3836(2)$ & & $681(3)$ & 4 \\
\hline 3 & 细小平裂藻 & Merismopedia minima & $4001(2)$ & $2039(3)$ & $2109(3)$ & & & 3 \\
\hline 4 & 湖泊伪 (假) 鱼腥藻 & Pseudoanabaena limnetica & $1243(4)$ & $4314(2)$ & $925(5)$ & & & 3 \\
\hline 5 & 微囊藻属 & Microcystis sp. & & & $1735(4)$ & $1659(2)$ & & 2 \\
\hline 1 & 针簇多肢轮虫 & Polyarthra trigla & $6560(1)$ & $5551(1)$ & $4045(1)$ & $4442(1)$ & $1084(3)$ & 5 \\
\hline 2 & 简弧象鼻溞 & Bosmina coregoni & $1124(5)$ & $865(5)$ & $2163(2)$ & $3157(2)$ & $1863(1)$ & 5 \\
\hline 3 & 萼花臂尾轮虫 & Brachionus calyciflorus & $1384(3)$ & $2183(2)$ & $1173(4)$ & $1574(3)$ & & 4 \\
\hline 4 & 暗小异尾轮虫 & Trichocerca pusilla & $1581(2)$ & $1428(3)$ & & & & 2 \\
\hline 5 & 前节晶囊轮虫 & Asplanchna priodonta & $1230(4)$ & & $1177(3)$ & & & 2 \\
\hline 1 & 铜锈环棱螺 & Bellamya aeruginosa & $3635(1)$ & $669(1)$ & $3369(1)$ & $3568(3)$ & & 4 \\
\hline 2 & 河蚬 & Corbicula fluminea & $2091(5)$ & $4335(5)$ & $570(5)$ & & $10238(3)$ & 4 \\
\hline 3 & 霍甫水丝蚓 & Limnodrilus hoffmeisteri & $1821(3)$ & $1601(3)$ & $5667(3)$ & $2456(3)$ & & 4 \\
\hline 4 & 苏氏尾鳃蚓 & Branchiura sowerbyi & $1171(2)$ & $1947(2)$ & $945(2)$ & & $670(3)$ & 4 \\
\hline 5 & 扭蚌 & Arconaia lanceolata & & & & & $2191(3)$ & 1 \\
\hline
\end{tabular}

* 括号内数值表示各水生生物排序 (按 IRI 值大小). 本表仅列出各区域 IRI 值前 5 位的水生生物种类 (优势种, IRI> $500)$. 
表 3 洪泽湖不同区域水生生物多样性指数“

Tab.3 Index of aquatic biodiversity in different regions of Lake Hongze

\begin{tabular}{|c|c|c|c|c|c|c|c|c|c|c|c|c|c|c|c|}
\hline \multirow{2}{*}{ 区域 } & \multicolumn{5}{|c|}{ 浮游植物 } & \multicolumn{5}{|c|}{ 浮游动物 } & \multicolumn{5}{|c|}{ 底栖动物 } \\
\hline & $D$ & $H^{\prime}{ }_{\mathrm{N}}$ & $H^{\prime}{ }_{W}$ & $J^{\prime}{ }_{\mathrm{N}}$ & $J^{\prime}{ }_{W}$ & $D$ & $H^{\prime}{ }_{\mathrm{N}}$ & $H^{\prime}{ }_{\mathrm{W}}$ & $J^{\prime}{ }_{\mathrm{N}}$ & $J^{\prime}{ }_{W}$ & $D$ & $H^{\prime}{ }_{\mathrm{N}}$ & $H^{\prime}{ }_{\mathrm{W}}$ & $J^{\prime}{ }_{\mathrm{N}}$ & $J^{\prime}{ }_{W}$ \\
\hline 河口 & 0.44 & 0.34 & 0.30 & 0.06 & 0.08 & 4.59 & 2.10 & 2.22 & 0.66 & 0.70 & 1.18 & 1.29 & 0.69 & 0.82 & 0.47 \\
\hline 湖心 & 0.13 & 0.05 & 0.22 & 0.00 & 0.07 & 4.29 & 2.27 & 1.93 & 0.68 & 0.58 & 1.15 & 1.45 & 0.39 & 0.81 & 0.24 \\
\hline 网围区 & 0.43 & 0.23 & 0.51 & 0.04 & 0.10 & 4.64 & 1.90 & 2.31 & 0.53 & 0.64 & 0.98 & 1.26 & 0.38 & 0.77 & 0.24 \\
\hline 拆除区 & 0.23 & 0.47 & 0.32 & 0.11 & 0.07 & 4.74 & 2.14 & 2.48 & 0.59 & 0.68 & 1.33 & 1.51 & 0.47 & 0.81 & 0.25 \\
\hline 外围区 & 0.33 & 0.47 & 0.35 & 0.10 & 0.09 & 4.46 & 2.33 & 2.36 & 0.67 & 0.67 & 1.26 & 1.38 & 1.07 & 0.72 & 0.59 \\
\hline
\end{tabular}

* 以水生生物密度及生物量分别计算水生生物多样性指数 (以下标 $\mathrm{N} 、 \mathrm{~W}$ 表示).

2.2.2 浮游动物群落变化 浮游动物在本次调查中共检测出 80 种, 其中轮虫 46 种 ( $57.5 \%$ ), 枝角类 18 种 $(22.5 \%)$, 桡足类 16 种 $(20.0 \%)$. 比较洪泽湖不同水域浮游动物种类组成, 结果显示养殖区浮游动物种类数 高于湖心和河口, 轮虫种类相对较多; 而养殖网围区、拆除区和外围区种类差别不明显. 各水域优势种主要 为轮虫和象鼻溞等小型浮游动物 (表 2), 包括针簇多肢轮虫 (Polyarthra trigla)、简弧象鼻溞 (Bosmina coregoni) 等. 不同区域间浮游动物的优势种及优势度存在明显差别, 其中养殖区和河口区排在前位的优势种 主要为轮虫和象鼻溞等小型浮游动物种类, 而湖心区的优势种中出现桡足类, 如汤匙华哲水蚤 (Sinocalanus dorrii), 养殖区内浮游动物优势种组成则相对一致 (表 2). 洪泽湖各水域基于个体数量的多样性指标 $H^{\prime}$ 、 $J^{\prime}{ }_{\mathrm{N}}$ 与基于生物量的多样性指标 $H^{\prime}{ }_{\mathrm{W}} 、 J^{\prime}{ }_{\mathrm{W}}$ 之间无明显差异, 且洪泽湖不同水域的浮游动物各项多样性指数亦 无显著差异 $(P<0.05)$. 各调查点位基于个体数量的多样性指标 $H^{\prime}{ }_{\mathrm{N}} 、 J^{\prime}{ }_{\mathrm{N}}$ 与基于生物量的多样性指标 $H^{\prime}{ }_{\mathrm{W}}$ 、 $J^{\prime}{ }_{W}$ 无明显的变化规律 (表 3), 且洪泽湖湖不同水域的各项多样性指数均无显著差异. 洪泽湖浮游动物 $D 、 H^{\prime}$ 和 $J^{\prime}$ 的计算结果显示 (表 3), 各区域浮游动物多样性均表现为较丰富.

洪泽湖不同水域间浮游动物密度和生物量亦存在明显差别 (图 $2 \mathrm{~b}$ ), 且趋势与浮游植物保持基本一致, 整体表现为养殖区高于湖心和河口; 而养殖网围区、拆除区和外围区在密度和生物量上差异并不明显, 这表 明网围拆除后的短期时间内浮游动物现存量并未发生明显变化. 研究认为, 水动力条件、水质因子和藻类是 影响浮游动物群落的主要原因 ${ }^{[32-33]}$. 其中养殖区的藻类生物量相对河口和湖心较高 (图 2a), 为浮游动物生 长提供了充足的覀料, 这是浮游动物密度增加的重要原因 ${ }^{[34]}$. 其次, Arauzo ${ }^{[35]}$ 的研究表明浮游动物生物量 与水体中氨氮浓度呈负相关, 这与本研究中的趋势相同 (表 1). 水动力条件亦是浮游动物的重要影响因子, 有研究发现水动力的扰动会增强浮游动物的代谢作用, 不利于浮游动物的生长量累积 ${ }^{[36]}$, 这可能也是养殖 区浮游动物密度高于河口和湖心的重要原因.

对比分析洪泽湖各区域浮游动物的组成结构, 发现养殖区以轮虫为主, 而湖心和河口以枝角类和桡足 类为主, 轮虫比重下降, 这可能与养殖区鱼类的下行捕食压力较大有关 ${ }^{[37]}$. 洪泽湖渔业管理委员会统计数 据显示洪泽湖网围养殖区多以浮游食性鱼类为主, 其中鲢、鳙鱼养殖产量分别占洪泽湖总养殖产量的 15\% 和 $58 \%$. 同时大量研究表明, 养殖鱼类造成的大型浮游动物牧食压力下降亦是造成养殖区浮游植物所占比 例较高的原因 ${ }^{[38]}$. 此外, 养殖区的浮游植物组成多以蓝藻等聚集态大颗粒藻类为主, 而小型浮游动物无法 有效摄食这些藻类种类,进而影响到其种群数量的维持与增长 ${ }^{[39]}$.

2.2.3 底栖动物群落变化 在本次调查中共检测出底栖动物 25 种, 隶属 3 门 6 纲, 其中昆虫纲 9 种, 腹足纲 与双壳纲各 5 种, 其他纲 $1 \sim 3$ 种. 洪泽湖不同区域间底栖动物的优势种及优势度存在差别: 养殖区各区域间 在优势种上无明显差异, 其优势物种多为霍甫水丝蚂 ( Limnodrilus hoffmeisteri)、苏氏尾鳃蚓 ( Branchiura sow$e r b y i$ ) 等污带指数种 (表 2); 河口和湖心与养殖区相比, 底栖动物优势种有所变化, 出现多毛纲、甲壳纲, 如拟 背尾水禹属一种 (Paranthura sp.) 等. 洪泽湖各区域生物多样性除外围区外均表现为贫乏 (表 3), 各多样性 指数在洪泽湖不同水域间无明显差异 $(P<0.05)$.

洪泽湖各区域的底栖动物种类数相近, 但其密度和生物量存在差别 (图 2c). 底栖动物密度从高到低依 次为河口 $>$ 外围区 $>$ 网围区 $>$ 拆除区 $>$ 湖心; 生物量从高到低依次为湖心 $>$ 网围区 $>$ 拆除区 $>$ 外围区 $>$ 
河口. 河口与养殖外围区密度较高, 分别为 151 和 $146 \mathrm{ind} . / \mathrm{m}^{2}$, 其中形体较小的寡毛纲所占比例较大. 这可 能是因为河口受人湖污水影响较大, 污染最为严重, 此种生境状况更有利于耐污染能力强的种类生存 ${ }^{[40]}$, 因 而寡毛纲在河口区域表现出绝对优势和高密度. 在湖心区较强的水动力条件下, 以藻类残体为食的小型底 栖动物食物源受到限制; 但较强的水动力条件,也更有利于河蚬等的滤食作用,这就表现为湖心小型底栖动 物密度较低而同时双壳纲所占比例较大 ${ }^{[41]}$. 而养殖区远离河口, 受人湖河流及风浪扰动较小, 更有利于浮 游植物和底栖藻类生长 ${ }^{[25]}$, 也为底栖动物提供了较适宜的生境条件 ${ }^{[40]}$, 因而在养殖区底栖动物密度亦 较高.

\section{3 结论}

1) 洪泽湖各区域的水质、底质分布特征存在明显差异, 其中湖心和河口水体氮、磷浓度显著高于养殖 区, 但其 Chl. $a$ 浓度则显著低于养殖区, 水动力条件引起的底质再悬浮是造成水质空间差异的主要原因; 此 外, 养殖区内网围区、拆除区和外围区的水体营养盐浓度并无显著差异, 表明网围拆除未能明显改善湖区 水质.

2) 洪泽湖网围养殖区浮游植物密度显著上升, 且群落组成中蓝藻比例增加, 同时浮游动物种群向小型 化演替; 当养殖区网围拆除后的浮游动植物现存量及群落结构并未发生明显变化, 且底栖动物种群也未出 现恢复迹象, 高藻类密度、低透明度的湖泊环境也不适合水生植物的萌发生长, 因此需结合其他合理的生态 修复技术促进养殖迹地生态系统的恢复.

\section{4 参考文献}

[ 1 ] Mao ZG, Gu XH, Gong ZJ et al. The structure of fish community and changes of fishery resources in Lake Hongze. J Lake Sci , 2019, 31(4) : 1109-1119. DOI: 10.18307/2019.0401. [毛志刚, 谷孝鸿, 龚志军等. 洪泽湖鱼类群落结构及其 资源变化. 湖泊科学, 2019, 31(4) : 1109-1119.]

[ 2 ] Fan YM, He HC, Cui YX et al. Dynamic analysis of water area in the lake of Hongze basin. Resources and Environment in the Yangtze Basin, 2010, 19(12) : 1397-1403. [范亚民, 何华春, 崔云霞等. 淮河中下游洪泽湖水域动态变化研究. 长江流域资源与环境, $2010,19(12): 1397-1403$.

[ 3 ] Zheng BH, Wang X. The study of aquaculture model based on the lake ecological security pattern. Environmental Protection, 2015, 43(11) : 47-50. [郑丙辉, 汗星. 基于湖库生态安全的水产养殖模式研究. 环境保护, 2015, 43(11): 47-50.]

[ 4 ] Wu TH, Liu JS, Deng JM et al. Community structure of phytoplankton and bioassessment of water quality in a large watercarrying lake, Lake Hongze. J Lake Sci, 2019, 31(2) : 440-448. DOI: 10.18307/2019.0213. [吴天浩, 刘劲松, 邓建 明等. 大型过水性湖泊——洪泽湖浮游植物群落结构及其水质生物评价. 湖泊科学, 2019, 31(2): 440-448.]

[ 5 ] Du X, Wang QD, Zhang CW et al. Community structure of rotifers in relation to environmental factors in Lake Hongze. $J$ Lake Sci, 2014, 26(2) : 269-276. DOI: 10.18307/2014.0214. [都雪, 王齐东, 张超文等. 洪泽湖轮虫群落结构及其 与环境因子的关系. 湖泊科学, 2014, 26(2) : 269-276.]

[ 6 ] Cai YJ, Zhang Y, Wu ZS et al. Composition, diversity, and environmental correlates of benthic macroinvertebrate communities in the five largest freshwater lakes of China. Hydrobiologia, 2017, 788(1): 85-98. DOI: 10.1007/s10750-0162989-y.

[ 7 ] Gu XH, Mao ZG, Ding HP et al. Progress and prospect of lake fishery in China. J Lake Sci, 2018, 30(1): 1-14. DOI: 10.18307/2018.0101. [谷孝鸿, 毛志刚, 丁慧萍等. 湖泊渔业研究: 进展与展望. 湖泊科学, 2018, 30(1): 1-14.]

[ 8 ] He XW, Chu Y, Zeng J et al. Effects of optimized fish farming on the sediment nutrients of eastern lake Taihu. Environmental Science, 2017, 38(11) : 4562-4569. DOI: 10.13227/j.hjkx.201705088. [何肖微, 储瑜, 曾巾等. 东太湖渔业 养殖对沉积物营养盐的影响. 环境科学, 2017, 38(11): 4562-4569.]

[ 9 ] Wang SM, Dou HS eds. Lakes in China. Beijing: Science Press, 1998: 268-271. [王苏民, 窦鸿身. 中国湖泊志. 北京: 科学出版社, 1998: 268-271.]

[10] Jin XC, Tu QY eds. Specifications for lake eutrophication survey: 2nd edition. Beijing: China Environmental Science Press, 1990. [ 金相灿, 屠清瑛. 湖泊富营养化调查规范: 第 2 版. 北京: 中国环境科学出版社, 1990. ] 
[11] Hu HJ, Wei YX eds. Freshwater algae in China-Systematics, classification and ecology. Beijing: Science Press, 2006. [胡鸿钧, 魏印心. 中国淡水藻类——系统、分类及生态. 北京: 科学出版社, 2006.]

[12] Wang JJ ed. Freshwater rotifers of China. Beijing: Science Press, 1961. [王家楫. 中国淡水轮虫志. 北京: 科学出版 社, 1961.]

[13] Michel, Tachet H eds. Translated by Liu W, Wang XT, Huang SF. Classification, biology and ecology of freshwater invertebrate systems. Beijing: China Water Conservancy and Hydropower Press, 2015. [ Michel, Tanchet Henri 著. 刘威, 王 旭涛, 黄少峰译. 淡水无脊椎动物系统分类、生物及生态学. 北京: 水利水电出版社, 2015.]

[14] Belaoussoff S, Kevan PG, Murphy S et al. Assessing tillage disturbance on assemblages of ground beetles ( Coleoptera: Carabidae) by using a range of ecological indices. Biodiversity \& Conservation, 2003, 12(5) : 851-882. DOI: 10.1023/ A: 1022811010951.

[15] Pinkas L, Oliphant, Iverson IL et al. Food habits of albacore, bluefin tuna, and bonito in California waters. Fishery Bulletin, 1971: 5-10.

[16] Shi WG, Wang B, Zhou X. Effects of pen fish and crab polyculture on burden of nitrogen and phosphorus in aquatic environment of weed-type lakes. J Lake Sci, 1999, 11(4) : 363-368. DOI: 10.18307/1999.0413. [施炜纲, 王博, 周昕. 蟹、鱼网围混养对草型湖泊氮磷平衡的影响. 湖泊科学, 1999, 11(4) : 363-368.]

[17] Qin BQ, Hu WP, Gao G et al. Dynamics of sediment resuspension and the conceptual schema of nutrient release in the large shallow Lake Taihu, China. Science Bulletin, 2003, 48(17) : 1822-1831. [秦伯强, 胡维平, 高光等. 太湖沉积物 悬浮的动力机制及内源释放的概念性模式. 科学通报, 2003, 48(17) : 1822-1831.]

[18] Zhu W, Zhou XH, Chen HM et al. High nutrient concentration and temperature alleviated formation of large colonies of Microcystis : Evidence from field investigations and laboratory experiments. Water Research, 2016, 101: 167-175. DOI: 10. 1016/j.watres.2016.05.080.

[19] Pang Y, Li YP, Luo LC. Study on the simulation of transparency of Lake Taihu under different hydrodynamic conditions. Science in China: Series D, 2005, 35(z2) : 145-156. [逢勇, 李一平, 罗潋葱. 水动力条件下太湖透明度模拟研究. 中国科学: D 辑, 2005, 35( z2) : 145-156.]

[20] Covino T. Hydrologic connectivity as a framework for understanding biogeochemical flux through watersheds and along fluvial networks. Geomorphology, 2017, 277: 133-144. DOI: 0.1016/j.geomorph.2016.09.030.

[21] Xue JZ, Cai Z, Fang W et al. Ecological status of plankton in Kunshan area of Dianshan Lake after aquaculture net dismantling. Journal of Shanghai University, 2010, 19(4): 514-520. [薛俊增, 蔡桢, 方伟等. 淀山湖养殖围网拆除后 昆山水域浮游生物生态现状初步研究. 上海海洋大学学报, 2010, 19(4) : 514-520.]

[22] Luo JH, Pu RL, Ma RH et al. Mapping long-term spatiotemporal dynamics of pen aquaculture in a shallow lake: Less aquaculture coming along better water quality. Remote Sensing, 2020, 12(11) : 1866. DOI: 10.3390/rs12111866.

[23] Sun XJ, Qin BQ, Zhu GW et al. Effect of wind-induced wave on concentration of colloidal nutrient and phytoplankton in lake Taihu. Environmental Science, 2007, 28(3) : 506-511. DOI: 10.13227/j.hjkx.2007.03.011. [孙小静, 秦伯强, 朱 广伟等. 风浪对太湖水体中胶体态营养盐和浮游植物的影响. 环境科学, 2007, 28(3): 506-511.]

[24] Cao HS, Kong FX, Luo LC et al. Effects of wind and wind-induced waves on vertical phytoplankton distribution and surface blooms of Microcystis aeruginosa in Lake Taihu. Journal of Freshwater Ecology, 2006, 21 (2) : 231-238. DOI: 10. 1080/02705060.2006.9664991.

[25] Visser AW, Stips A. Turbulence and zooplankton production: Insights from PROVESS. Journal of Sea Research, 2002,47 (3/4) : 317-329. DOI: 10.1016/S1385-1101(02)00120-X.

[26] Hondzo M, Lyn D. Quantified small-scale turbulence inhibits the growth of a green alga. Freshwater Biology, 1999, 41 (1) : 51-61. DOI: 10.1046/j.1365-2427.1999.00389.x.

[27] Granstedt A. Optimizing nitrogen management in food and energy production, and environment change. AMBIO: A Journal of the Human Environment, 2002, 31(6) : 496-497. DOI: 10.1579/0044-7447-31.6.496.

[28] Qin BQ, Yang GJ, Ma JR et al. Dynamics of variability and mechanism of harmful cyanobacteria bloom in Lake Taihu, China. Chinese Science Bulletin, 2016, 61(7)：759-770. [秦伯强, 杨桂军, 马健荣等. 太湖蓝藻水华 “暴发” 的动态 特征及其机制. 科学通报, 2016, 61(7): 759-770.]

[29] Huisman J, Sharples J, Stroom JM et al. Changes in turbulent mixing shift competition for light between phytoplankton species. Ecology, 2004, 85(11) : 2960-2970. DOI: 10.1890/03-0763. 
[30] Paerl HW, Hall NS, Calandrino ES. Controlling harmful cyanobacterial blooms in a world experiencing anthropogenic and climatic-induced change. Science of the Total Environment, 2011, 409(10) : 1739-1745. DOI: 10.1016/j.scitotenv.2011. 02.001 .

[31] Wilhm JL. Use of biomass units in shannon's formula. Ecology, 1968, 49(1) : 153-156. DOI: 10.2307/1933573.

[32] Li Y, Xie P, Zhang J et al. Effects of filter-feeding planktivorous fish and cyanobacteria on structuring the zooplankton community in the eastern plain lakes of China. Ecological Engineering, 2017, 99: 238-245. DOI: 10.1016/j. ecoleng. 2016.11.040.

[33] George DG, Winfield IJ. Factors influencing the spatial distribution of zooplankton and fish in Loch Ness, UK. Freshwater Biology, 2000, 43(4) : 557-570. DOI: 10.1046/j.1365-2427.2000.00539.x.

[34] Wang XM, Song XM. Investigation on relevance between zooplankton in GaoTang Lake and water environmental factors in Huainan City. Journal of Beijing Institute of Education: Natural Science Edition, 2007, 2( 5) : 19-23. [王晓明, 宋晓梅. 淮南市高塘湖浮游动物与水环境因子的相关性研究. 北京教育学院学报: 自然科学版, 2007, 2(5): 19-23.]

[35] Arauzo M. Harmful effects of un-ionised ammonia on the zooplankton community in a deep waste treatment pond. Water Research, 2003, 37 (5) : 1048-1054. DOI: 10.1016/S0043-1354(02)00454-2.

[36] Visser AW, Mariani P, Pigolotti S. Swimming in turbulence: Zooplankton fitness in terms of foraging efficiency and predation risk. Journal of Plankton Research, 2009, 31(2) : 121-133. DOI: 10.1093/plankt/fbn109.

[37] Iglesias C, Mazzeo N, Meerhoff M et al. High predation is of key importance for dominance of small-bodied zooplankton in warm shallow lakes: Evidence from lakes, fish exclosures and surface sediments. Hydrobiologia, 2011, 667 (1) : 133-147. DOI: $10.1007 / \mathrm{s} 10750-011-0645-0$.

[38 ] Jeppesen E, Jensen JP, Søndergaard M et al. Impact of fish predation on cladoceran body weight distribution and zooplankton grazing in lakes during winter. Freshwater Biology, 2004, 49 (4) : 432-447. DOI: 10. 1111/j. 1365-2427.2004. 01199.x.

[39] Bernardi R, Giussani G. Are blue-green algae a suitable food for zooplankton? An overview. Hydrobiologia, 1990, 200/ 201( 1 ) : 29-41. DOI: 10.1007/BF02530326.

[40] da Cunha Lana P, Guiss C. Influence of Spartina alterniflora on structure and temporal variability of macrobenthic associations in a tidal flat of Paranagua Bay (southeastern Brazil). Marine Ecology Progress Series, 1991, 73: 231-244. DOI: 10. 3354/meps073231.

[41] Cai YJ, Gong ZJ, Qin BQ. Community structure and diversity of macrozoobenthos in Lake Taihu, a large shallow eutrophic lake in China. Biodiversity Science, 2010, 18(1): 50-59. [蔡永久, 龚志军, 秦伯强. 太湖大型底栖动物群落结构及 多样性. 生物多样性, 2010, 18(1): 50-59.] 